\title{
PROGRAMA DE ESCOLAS INTERCULTURAIS DE FRONTEIRA (PEIF): UM DESAFIO PARA AS ESCOLAS NO MUNICÍPIO DE PONTA PORÃ
}

\section{PEIF - Border Intercultural School Program - a challenge for schools in the punta porã municipality}

Maria Elena Aquino Dutra - UFMS /Brasil Rozana Vanessa Fagundes Valentim de Godoi - UFMS/Brasil

\begin{abstract}
RESUMO: O objetivo deste artigo é discutir sobre a importância do Programa denominado Escolas Interculturais de Fronteira (PEIF) no município de Ponta Porã, destacando as formas de implantação, os países participantes, assim como refletir sobre sua importância para as escolas situadas nas regiões de fronteira. Para a realização deste trabalho realizou-se uma pesquisa bibliográfica em sites de pesquisa como Google Acadêmico, Portal do Ministério da Educação (MEC) e o Projeto Político Pedagógico (PPP) que trazem informações sobre o programa de formação continuada em regiões de fronteira, a amostra foi composta de em livros, artigos ciêntificos, leis, decretos entre outros documentos pertinentes ao tema. Destaca-se informações sobre o programa, como também apresenta-se uma reflexão sobre a importância dos cursos de formação continuada para professores que atuam em áreas ou regiões de multiculturalismo linguístico e cultural, buscando dessa maneira não só conhecer o programa, mas também as leis que amparam os direitos das crianças quanto a uma educação que vise não só a aprendizagem, mas principalmente o respeito com os diferentes tipos de cultura. Por meio da pesquisa realizada foi possível conhecer um pouco sobre o Programa Escolas Interculturais de Fronteira além de refletir sobre o papel dos programas de formação continuada na vida dos educadores, sua importância e necessidade.
\end{abstract}

Palavras-chave: Intercultura. Fronteira. Formação Continuada. Professor.

ABSTRACT: The aim of this paper is to discuss about the importance of the Program called Intercultural Border Schools (PEIF) in the city of Ponta Porã, highlighting the forms of implementation, the participating countries, as well as reflecting on its importance for schools located in border regions. To carry out this work, a bibliographic search was carried out in research sites such as Google Scholar, Ministry of Education Portal (MEC) and the Pedagogical Political Project (PPP) that bring information about the continuing education program in border regions, the The sample consisted of books, scientific articles, laws, decrees and other relevant documents. Information about the program is highlighted, as well as a reflection on the importance of continuing education courses for teachers working in areas or regions of linguistic and cultural multiculturalism, seeking not only to know the program, but also the laws, that support children's rights to an education that aims not only at learning, but especially at respecting different types of culture. Through the research carried out it was possible to know a little about the Intercultural Border Schools Program and to reflect on the role of continuing education programs in the lives of educators, their importance and need.

Educação, Psicologia e Interfaces, Volume 3, Número 3, p. 35-47, Setembro/Dezembro, 2019. ISSN: 2594-5343. DOI: https://doi.org/10.37444/issn-2594-5343.v3i3.209 
Keywords: Interculture. Border. Teacher. Continuing Education.

\section{INTRODUÇÃO}

Os municípios de Ponta Porã e Pedro Juan Caballero estão ligados por uma faixa de fronteira seca que permite não só o contato direto econômico e político, mas também um contato cultural, pois em ambos os países Brasil/Paraguai existem relações não só culturais, mas de laços familiares.

Segundo Jordan (1996 apud CANDAU, 2012) os termos intercultural e multicultural são frequentemente empregados como sinônimos, no entanto, apesar dessa comparação, seus significados são diferentes, pois o multiculturalismo é a existência de diferentes culturas, e o interculturalismo é uma relação de reciprocidade entre essas diferentes culturas, sendo que isto está presente dentre das escolas a todo momento, principalmente onde a relação entre as culturas está diretamente ligada.

Candau (2012) considera o interculturalismo como um enfoque que afeta a educação em todas as suas dimensões, favorecendo uma dinâmica de crítica e autocritica, valorizando a interação e comunicação reciprocas, entre os diferentes sujeitos e grupos sociais. Orienta processos que tem por base o reconhecimento do direito a diferença e a luta contra todas as formas de discriminação e desigualdade social.

Sendo assim, os educadores que atuam nas regiões fronteiriças, onde há o contato direto com diferentes culturas, tem que estar atentos às práticas pedagógicas que irão realizar, de forma que não venham a desrespeitar ou desvalorizar aqueles que tem uma forma de vida diferente dos demais estudantes.

O presente trabalho tem o objetivo de discutir sobre a importância do Programa denominado Escolas Interculturais de Fronteira (PEIF) no município de Ponta Porã, destacando as formas de implantação, os países participantes, assim como refletir sobre sua importância para as escolas situadas nas regiões de fronteira.

\section{MATERIAL E MÉTODO}

Esta pesquisa foi realizada por meio de pesquisa bibliográfica, utilizando sites de pesquisa como Google Acadêmico, Portal do Ministério da Educação (MEC) e o Projeto Político Pedagógico (PPP), que trazem informações sobre o programa de formação 
continuada em regiões de fronteira. Os materiais utilizados foram livros, artigos científicos, leis, decretos e documentos pertinentes ao tema.

De acordo com com Markoni e Lakatos (2003) pesquisa bibliográfica é um apanhado sobre trabalhos já realizados, fornecendo dados atuais e relevantes ao tema, podendo ser utilizadas fontes primárias e secundárias para a realização da mesma. Os dados selecionados foram resumidos e resenhados, o conteúdo foi utilizado em forma de texto na estruturação deste artigo.

\section{RESULTADOS E DISCUSSÃO}

De acordo com dados do MEC (2018), o PEIF teve origem em declaração conjunta formada em Buenos Aires, em 2004, entre os Ministérios da Educação, Ciência e Tecnologia da Argentina e do Brasil, estabelecendo a troca de experiências entre estudantes e professores de escola públicas brasileiras e argentinas. O intercambio começou em 2005, e, em 2009 foi ampliado com a inclusão do Uruguai, Paraguai e Venezuela, logo depois para a Bolívia.

O Programa Escolas Interculturais de Fronteira veio a ser instituído no Brasil pela Portaria $\mathrm{n}^{\mathrm{o}} 798$, de 19 de junho de 2012, com o objetivo de contribuir para a formação integral de crianças, adolescentes e jovens, por meio da articulação de ações que visem à integração regional por meio da educação intercultural das escolas públicas de fronteira, alterando o ambiente escolar e ampliando a oferta de saberes, métodos, processos e conteúdos educativos. O programa segue princípios relacionados ao interculturalismo e bilinguismo, assim como o Projeto Político Pedagógico das escolas envolvidas sendo construídos comum e coletivamente.

Desse modo, fica claro que uma das principais funções do programa foi incentivar e promover o respeito com as demais culturas, de forma que possa diminuir e erradicar o preconceito e a discriminação para com o outro, além de descontruir antigas concepções, passando a construir novos modelos e práticas de ensino que valorizem a diferença e as características de cada cultura.

Para Borges (2014) o Programa Escolas Interculturais de Fronteira, desenvolveuse como uma ação necessária para a construção e o fortalecimento de políticas educacionais voltadas as faixas de fronteira do Brasil, a partir da possibilidade de 
integração de todos os processos educativos da escola, com vistas a construção de um projeto político pedagógico que tenha como ponto de partida a interculturalidade.

As ações realizadas pelo programa não só favoreceram as escolas ou aos estudantes, mas toda a comunidade externa, que de certa forma está envolvida em todo o meio cultural, pois por meio das atividades realizadas é possível não só mover elementos educacionais, mas também os políticos, econômicos e sociais que estão interrelacionados.

De acordo com dados do MEC (2018) o programa Intercultural de Fronteiras até 2013 era desenvolvido em 17 unidades de ensino do Brasil e 15 da Argentina, Bolívia, Paraguai, Uruguai e Venezuela, em 2014 agregou municípios do Brasil que fazem fronteira com o Peru, Colômbia Guiana e Guiana Francesa.

Até o ano de 2014 faziam parte do programa as Universidade Federais do Pampa (Unipampa), de Santa Maria (UFSM), do Rio Grande do Sul (UFRGS), de Pelotas (UFPel), de Mato Grosso do Sul (UFMS), da Integração Latino-Americana (Unila), da Grande Dourados (UFGD), do Rio Grande (Furg), de Roraima (UFRR) e da Fronteira Sul (UFFS), e em 2014, iriam ingressar as do Acre (Ufac), do Amazonas (Ufam), do Paraná (UFPR) e de Rondônia (Unir).

Percebe-se por meio do projeto, que a interação universidade-escola está presente e é necessária para que possa ocorrer um entrelaçamento entre ambos, pois o contato das escolas de educação básica com as universidades pode alavancar grandes mudanças ao meio educacional, principalmente no que diz respeito a profissão docente.

De acordo com Torquato e Lorenzetti (2016) o Projeto Escolas Interculturais de Fronteira (PEIF) tem por objetivo promover o intercâmbio entre os professores do Mercosul, focalizando na quebra de fronteira, além de ampliar as oportunidades de aprendizagem da segunda língua, utilizando a metodologia de ensino com projetos de aprendizagem. No ano de 2007 foi apresentado o Modelo de ensino comum de zona de fronteira que tinha por objetivo estabelecer as metas e as formas de aplicação do projeto nas regiões de fronteira.

O intercambio não ocorre somente entre os docentes participantes do projeto, mas também com os estudantes das escolas que participam ativamente das atividades juntamente com seus professores, de maneira a fomentar uma aprendizagem mais significativa para ambos, docentes e estudantes. A partir de sua instituição o Projeto 
passou a ser Programa, ou seja, vários projetos coordenados de forma dinâmica com objetivos em comum, que neste caso é a educação intercultural de fronteira.

Além de possuir a integração e o auxílio das universidades federais, o Governo Federal por meio do Ministério da Educação procurou incentivar os participantes com bolsas de auxilio, pois segundo o Fundo Nacional de Desenvolvimento da Educação (FNDE, 2018) o objetivo do programa visa à formação continuada de professores que atuam em escolas situadas em zonas de fronteira entre o Brasil e outros países.

A ideia foi integrar professores e estudantes brasileiros com professores e estudantes dos países vizinhos ampliando as oportunidades de aprendizado da segunda língua, tendo como parceiras as Instituições de Ensino Superior, Escolas de Aplicação, Institutos Federais de Educação Ciência e Tecnologia que seriam responsáveis por ministrar os cursos de formação, selecionar e cadastrar os bolsistas. Essas Instituições também tinham a função de encaminhar mensalmente ao gestor nacional o lote de bolsistas a serem pagos, assim como às Secretarias de Educação responsáveis por coordenar as atividades no seu âmbito de atuação e por oferecer espaço físico e infraestrutura para a realização da formação.

O programa é relevante, pois o Brasil possui uma extensa área de fronteira e isso acaba por promover a fusão entre as diferentes culturas e línguas existentes, a facilidade com que as pessoas têm de se deslocar de um país para outro, faz com que a fusão entre as culturas ocorra em quase todos os lugares, gerando uma grande miscigenação. As diferenças do setor socioeconômico promovem ainda mais esse hibridismo, pois alguns deixam de estudar ou trabalhar no seu país para ir para outro, devido as comodidades e facilidades econômicas, financeiras e sociais.

Um outro fator que chama atenção é com relação a discriminação e o preconceito que permeiam essas relações, isso pode ser percebido na fronteira Brasil/Paraguai com relação ao guarani, pois muitas vezes essa língua é vista como uma língua feia, ou que no comércio local ninguém entende, isso faz com que muitos prefiram aprender o português para que possam romper barreiras da comunicação e não sofrer o preconceito.

Considerando que as escolas paraguaias de Pedro Juan Caballero são pequenas, simples, sem a sofisticação presente nas escolas públicas do lado brasileiro, é possível que isto permita julgamentos improcedentes. O salário dos professores paraguaios é menor que o dos professores

Educação, Psicologia e Interfaces, Volume 3, Número 3, p. 35-47, Setembro/Dezembro, 2019. ISSN: 2594-5343. DOI: https://doi.org/10.37444/issn-2594-5343.v3i3.209 
brasileiros; as escolas brasileiras são equipadas com sala de tecnologia; os alunos recebem o kit escolar contendo o material básico, como cadernos, livros e camisetas. A escola paraguaia não tem nenhum destes recursos. Na escola brasileira, o padrão de interação é dinâmico, de tal forma que o aluno tem liberdade de interromper o turno de fala de seu professor e questionar, pedir explicação, dar exemplos. É permitido "desarrumar" as filas organizadas das carteiras onde sentam. Em contrapartida, estas atitudes não são praticadas nas escolas do lado paraguaio (PEREIRA, 2014, p. 18, 19).

Portanto, pode-se dizer que os cidadãos da cidade vizinha, Ponta Porã e das regiões divididas por fronteira seca, ou as cidades gêmeas deixam de matricular seus filhos em escolas da cidade onde vivem, para matricular no outro país devido as condições relacionadas a material escolar de qualidade, o ensino que tem maior acesso a tecnologia, assim como a própria alimentação das crianças, pois o lanche oferecido pelas escolas dos estados ou de municípios brasileiros são considerados como melhores. Com relação a língua o processo é quase o mesmo, pois o preconceito faz com que os estudantes paraguaios venham negar a sua própria identidade, tanto linguística quanto cultural para poderem ser mais bem aceitos pelos povos fronteiriços.

\subsection{O PEIF no município de Ponta Porã e seus benefícios}

O município de Ponta Porã está localizado na região Sul do estado do Mato Grosso do Sul, assim como outras regiões do país, este faz fronteira com a cidade de Pedro Juan Caballero no Paraguai, sendo separados apenas por uma linha divisória, portanto tem uma fronteira seca, sendo que algumas outras cidades da região de fronteira que são divididas por uma ponte ou apenas por rios (Figura 1).

Figura 1 - Ponta Porã - Brasil/ Pedro Juan Caballero - Paraguay

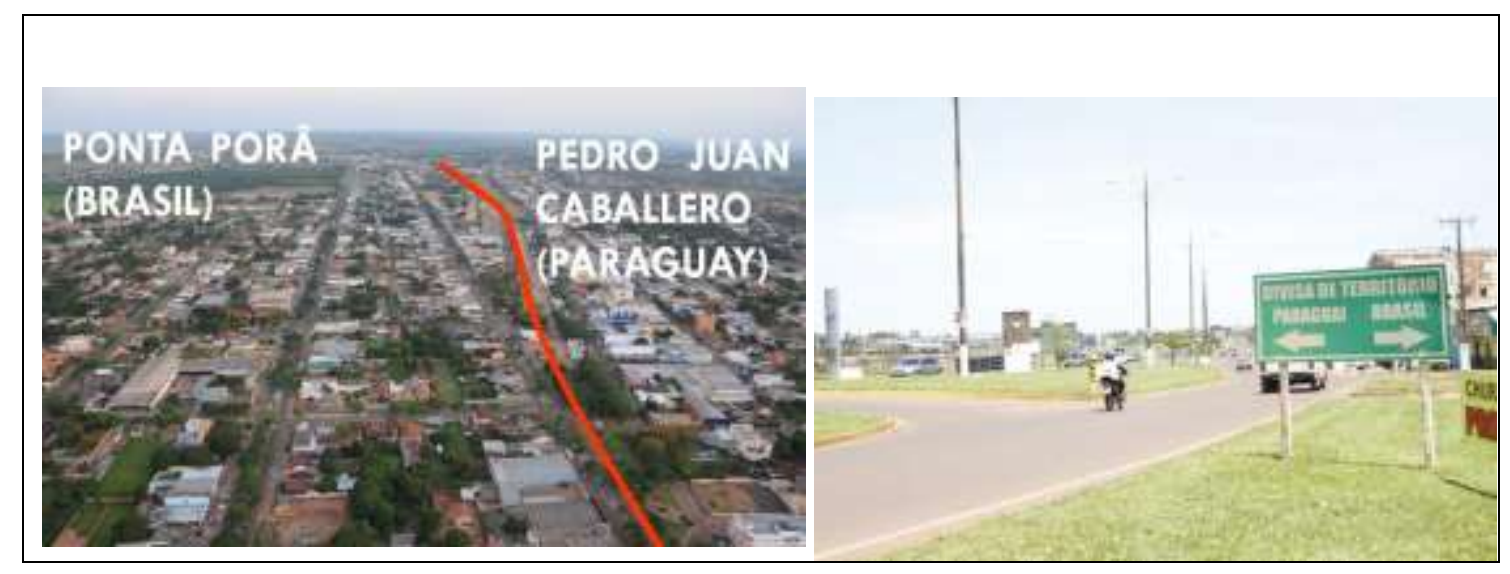


Programa de Escolas Interculturais de Fronteira (PEIF): um desafio para as escolas no Município de Ponta Porã

Fonte: Google fotos (2018)

Ao observar as fotos da figura 1 nota-se a facilidade de acesso que as cidades possuem entre si, pois estão separadas por apenas uma rua. É diante dessa facilidade que os moradores possuem livre circulação em ambas as cidades, permitindo assim relações econômicas e sociais intensas. Muitos brasileiros residem em Pedro Juan Caballero - PY, assim como muitos paraguaios residem em Ponta Porã - BR, este intercambio logístico promove a relação entre as culturas, sendo que muitas crianças são filhos de brasileiros com paraguaios e vice-versa, gerando uma miscigenação cultural.

$\mathrm{O}$ fato das cidades serem separadas por apenas uma rua permite o trânsito de veículos e pessoas naturalmente, o comércio é a principal fonte de renda dos cidadãos paraguaios e brasileiros da linha de fronteira. Tendo essa facilidade de acesso, assim como para obtenção de documentação, muitos paraguaios registram seus filhos no território brasileiro para que estes possam ter acesso a atendimento médico no Brasil, pois consideram o atendimento médico brasileiro mais eficiente, assim como também a possibilidade de colocar seus filhos para estudarem nas escolas de Ponta Porã, que acreditam ter melhor ensino.

A região é composta por miscigenação cultural, os paraguaios tem por língua oficial o castelhano e o guarani, mas além de falar estes idiomas também falam o português que aprenderam com seus pais ou com colegas brasileiros. No entanto, muitos dos paraguaios falam apenas o guarani, e quando seus pais os matriculam em uma escola do Brasil, estes tem dificuldade em se comunicar, assim como os professores tem dificuldade para ensinar, pois na maioria das vezes os professores não falam ou não entendem o idioma que a criança fala e vice-versa.

Segundo Candau e Moreira (2008), no momento atual, as questões culturais não podem ser ignoradas pelos educadores e educadoras, sob o risco de que a escola cada vez se distancie mais dos universos simbólicos, das mentalidades e das inquietudes das crianças e jovens. Portanto diante da teoria desse autor é papel da escola, por mais que tenha dificuldades para ensinar as crianças oriundas de outro país, procurar meios de se adequar a eles e buscar novos métodos e meio de ensino, para que a criança tenha uma 
aprendizagem de maneira adequada sem deixar de lado ou desvalorizar a sua língua materna e a sua cultura.

O município de Ponta Porã recebe em suas escolas constantemente alunos oriundos do Paraguai, e por possuir essa característica o município pode aderir ao Programa Intercultural de Fronteira. O projeto começou no Mato Grosso do Sul em outubro de 2008, para o qual foram feitos diagnósticos sociolinguísticos com as comunidades escolares onde as escolas participantes estão inseridas, sendo realizados pelo MEC, a Secretaria de Educação (SED) e o Instituto de Investigação e Política Linguística (IPOL) que presta assessoria ao projeto (FERNANDES, 2013).

Por meio desse levantamento sociolinguístico verificou-se que a escola Estadual Joao Brembati Calvoso possuía em média mil e oitocentos alunos, os quais falavam fluentemente o espanhol e o guarani, sessenta por cento iniciavam a vida escolar no $1^{\circ}$ ano do ensino fundamental e tinham como língua materna o guarani e o espanhol, sendo alfabetizados com uma língua que não conheciam (FERNANDES, 2013).

Para que a escola pudesse ser uma das integrantes do projeto foi necessário uma análise a respeito da composição de seu contexto escolar, como a escola Brembati Calvoso fica a apenas 250 metros do Paraguai, ela era e ainda é composta por muitos alunos paraguaios, sendo que o caso dessa escola não é o único, mas de outras escolas municipais e estaduais existentes no município. O projeto teve a participação de uma escola brasileira e de uma escola paraguaia, onde professores da escola do Brasil ministravam aula na escola paraguaia e os professores da escola paraguaia ministravam aula na escola brasileira.

É importante destacar que o papel dos professores não era ensinar o espanhol ou o guarani, mas sim ensinar os conteúdos nessa língua, que o programa não se baseava apenas em dar aulas, mas em realizar todo um planejamento em conjunto, principalmente a formulação do Projeto Político Pedagógico (PPP) integrando os requisitos necessários a valorização e respeito para com a língua e a cultura de ambos os cidadãos fronteiriços.

De acordo com o Projeto Político Pedagógico (2017) da escola Brembati Calvoso, em 2008 o projeto foi desenvolvido entre esta e a Escuela Generacion de La Paz, e que a partir do ano de 2009 passou a ser desenvolvido pela Escuela Básica 290- Defensores Del Chaco. Hoff, Fernandes e Beck (2016) afirmam que "desde o período de 2009 a 2012 , ambas as escolas participaram efetivamente do Programa”. 
Acontecimentos políticos interferiram no então projeto, pois com a suposta saída do Paraguai do Mercosul fez com que terminasse o intercâmbio entre as escolas participantes, mas segundo relatos dos professores apontados por Fernandes (2013) o programa trouxe muitos benefícios não só para os professores e estudantes, mas para a comunidade escolar em geral.

Esse projeto trouxe um avanço incalculável para a comunidade escolar da Escola Estadual João Brembatti Calvoso e para todos os educadores que trabalham aqui, hoje não só reconhecemos essas línguas no ambiente escolar como também incentivamos o seu uso com projetos que valorizam essas práticas, assim, temos a comunidade bem mais presente e os alunos aprendem muito mais, como demonstram os índices de desempenho da escola como o IDEB (Índice de Desenvolvimento da Educação Básica) ano base 2009 (FERNANDES, 2013, p.13).

Mesmo com a finalização do programa entre as escolas citadas acima, a Universidade Federal da Grande Dourados (UFGD) continuou conveniada ao Ministério da Educação e recebendo verba do PDDE para dar continuidade no processo de formação continuada de professores da cidade de Ponta Porã, do qual também foram convidados os professores da Escuela Defensores Del Chaco para participarem. Os cursos foram realizados em 2013 e 2014 com a participação de seis escolas municipais de Ponta Porã que estavam conveniadas ao programa.

Conforme Beck, Hoff e Fernandes (2016) a UFGD realizou cursos presenciais e a distância para os professores, que segundo suas analises declararam que os cursos promoveram a reflexão acerca da vivência na fronteira e a influência de cultura na educação, mas que foi excessivamente teórico, e, em 2014 com a elaboração de novo curso e com ampliação de mais vagas para os professores de escolas públicas que aderiram ao PEIF em seis municípios, trouxe novas reflexões sobre a fronteira. No entanto, os participantes apontaram que o programa visou apenas os professores novos que entraram no programa e não considerou as necessidades dos professores que estavam desde 2009, repetindo conteúdos já ministrados, não pensando nas necessidades dos professores antigos das escolas.

Analisando as informações, nota-se que apesar dos cursos de formação continuada terem um cunho de auxílio ao professor, muitas vezes se tornam repetitivos e sem nexo para os participantes antigos, pois deixam de atender a necessidade real de professores e 
das escolas, é necessário que se ouça o que estes pensam, quais seus anseios e dificuldades, dessa forma podendo refletir sobre o que pode ser melhorado e ampliado para atender a todos os participantes, sejam eles iniciantes ou não. Em 2015, as atividades de formação continuada realizada pela UFGD se encerraram devido ao fato de não receber mais verbas do Governo Federal para a realização do programa.

De acordo com participantes do programa, que relataram a Fernandes (2013), este favoreceu muito para esclarecer e desconstruir conceitos e valores, assim como para aprender a respeitar as diferenças entre as línguas e a cultura dentro da escola e da sala de aula, pelos próprios professores e gestores da escola, que viam a língua como um empecilho para a aprendizagem, portanto para eles foi extremamente significativo.

\begin{abstract}
Mas, com o passar do tempo esta atitude mudou, hoje eles se sentem valorizados e tem sua identidade cultural preservada, sentem orgulho de ser trilíngues e se expressam na sua língua materna nos mais variados ambientes escolares, recreio, reuniões de pais, eventos culturais na escola, e até mesmo no dia a dia na escola os pais chegam à secretaria da escola e falam em espanhol e sabem que serão compreendidos e percebem que tem sua identidade cultural reconhecida e respeitada por todos na comunidade escolar (FERNANDES, 2013, p. 55).
\end{abstract}

Nesse mesmo sentido, Lorenzetti e Torquato (2016) relatam que o PEIF, na região de São Borja e Corrientes na fronteira com a Argentina tiveram seus recursos destinados ao Programa cortados pelo Governo Federal devido a situação econômica do país em 2015, pois os gastos com a manutenção do mesmo estava fora do orçamento. Os participantes da pesquisa dos autores relatam que o Programa trouxe auxílio aos professores em relação à aprendizagem educacional, mas que não é rentável para os docentes devido aos salários serem muito inferiores e possuírem diferença em relação aos participantes, o que torna desmotivador para os que fazem parte dele.

Tanto pelo lido e apontado em documentos, como pelo observado em campo, podemos afirmar que o PEIF tem carências desde sua origem. Em primeiro lugar, a maioria das questões que ficaram para se resolver durante o andamento do Programa permaneceram iguais ou apareceram novas questões. Encarou-se uma ampliação do programa sem terem resolvido temas, tais como:

- a remuneração equitativa dos professores: uns recebem por integrar o PEIF; para outros, trata-se de uma carga extra não remunerada. Essa decisão ficou a cargo das diferentes administrações, produzindo um desequilíbrio de expectativas e gerando desconforto entre aqueles que se acham em desvantagem; 
- o financiamento: sem previsão de orçamento, sem um organismo único ou organismos paralelos com idênticas funções, o financiamento depende da vontade das gestões e suas possibilidades. Quando os Governos Federais desaparecem como fornecedores, a proposta fica à deriva (LORENZETI; TORQUATO, 2016, p. 98- 99).

Novamente surgem relatos a respeito da falta de incentivo por parte de Governo Federal nesse tipo de programas, que segundo os docentes participantes é útil para a aprendizagem e valorização da língua e da cultura, assim como são eficazes dentro de contexto escolar das instituições participantes e parceiras, apesar de apresentar alguns problemas, segundo os relatos o Programa foi útil a comunidade escolar.

Diante desses relatos e problemas apontados, surge a pergunta: por que um Programa que deu certo na maioria das regiões em que foi realizado foi deixado de lado pelo governo? Se muitas das escolas apresentaram resultados positivos, por que não se pensou em novas soluções para os problemas apontados pelos educadores para que o Programa pudesse continuar? Para resposta desses questionamentos, é importante que novas pesquisas sejam realizadas, ficando em aberto para futuros pesquisadores interessados no tema.

\section{CONSIDERAÇÕES FINAIS}

Constatou-se que apesar do Programa Intercultural de Escolas de Fronteira ter sido pouco utilizado pelas escolas do Município de Ponta Porã, este trouxe grandes benefícios para os educadores, estudantes e toda a comunidade escolar que dele participou, sejam ela escolas Estaduais, Municipais e Instituições de Ensino Superior, pois as atividades realizadas permitiram uma maior reflexão a respeito do contexto de fronteira e sua interferência na educação.

Pois é partir da participação coletiva e do debate e discussão que surgem novas ideias e novos métodos capazes de auxiliar a todos os envolvidos nas atividades escolares, sejam elas curriculares ou não. E também é por meio de pesquisas a respeito desse tipo de programas que podemos perceber a sua utilidade para a sociedade em geral, assim como é possível analisar a respeito da importância dada pelo governo aos projetos de incentivo a educação e como este vem auxiliando e incentivando essas atividades. 
Mas, uma coisa a se pensar é a respeito do fim do programa na região de Ponta Porã, pois se o mesmo obteve resultados positivos dentro das escolas participantes, por que o Governo cortou incentivos? Ou por que não pensou em meios alternativos para trazer melhoras ao programa, a fim de não permitir o seu término na região?

O pensamento hipotético que se tem a respeito, é que a política acaba por interferir no meio educacional do país, afetando aqueles que mais necessitam de uma educação de qualidade, não só os estudantes, mas também os profissionais da educação que não só nas regiões fronteiriças, mas em todo o país acabam enfrentando situações difíceis e precisam de apoio por parte dos administradores da educação.

\section{REFERÊNCIAS BIBLIOGRÁFICAS}

BECK, Marta Costa; FERNANDES, Eliane Aparecida Araújo; HOFF, Sandino. Escolas Interculturais de Fronteira e as Relações com o Desenvolvimento Local 2009 a 2015. Revista Espacios, vol.37, n 05 , p. E - 2, Ano 2016.

BRASIL, Ministério da Educação. Escolas de Fronteira. Disponível em: <http://portal.mec.gov.br/ultimas-noticias/211-218175739/19218-programaintercultural-tera-mais-paises-cidades-e-idiomas>. Acessado em junho de 2018.

BRASIL, Ministério da Educação. Fundo Nacional de Desenvolvimento da Educação (FNDE). Disponível em: <http://www.fnde.gov.br/programas/dinheiro-diretoescola/dinheiro-direto-escola-apresentacao>. Acessado em junho de 2018.

CANDAU, Vera Maria. Didática crítica intercultural; aproximações. Petrópolis: Vozes, 2012.

FERNANDES, Eliane Aparecida Araújo. Experiências linguísticas: Como se faz a educação bilíngue com implementação da metodologia do projeto escola intercultural bilíngue de fronteira na fronteira entre Brasil e Paraguai. Dissertação (Pós-Graduação Strictu Sensu) Universidade Federal da Grande Dourados (UFGD). Dourados - MS, 2013

LORENZETTI, Alejandro; TORQUATO, Cloris Porto. O Programa Escolas Interculturais de Fronteira (PEIF) como política linguística. Revista Matraga, Rio de Janeiro, v.23, n.38, jan./jun. 2016.

MOREIRA, Antônio Flavio; CANDAU, Vera Maria. Multiculturalismo: Diferenças Culturais e Práticas Pedagógicas. 2.ed. Petrópolis: Vozes, 2008.

PEREIRA, Maria Ceres. Experiências, vivências e o imaginário na fronteira seca do sul de Mato Grosso do Sul. Programa Salto para o Futuro, TV Escola. Ano XXIV Boletim 1 - Maio, 2014. 
VALLE, Jacira Helena do; CALARGE, Carla Fabiana Costa. Escola Intercultural de Fronteira: Brasil/Bolívia, Campo Grande, MS: UFMS, 2013.

PEREIRA, Mauricio Gomes. A introdução de um artigo científico. Epidemiol. Serv.

Saúde, Brasília, v. 21, n. 4, p. 675-676, dez. 2012 . Disponível em <http://scielo.iec.pa.gov.br/scielo.php?script=sci_arttext\&pid=S1679-

49742012000400017\&lng=pt\&nrm=iso>. Acesso em: 01 nov. 2017. http://dx.doi.org/10.5123/S1679-49742012000400017

\section{Credenciais das autoras}

DUTRA, Maria Elena Aquino. Graduanda do $8^{\circ}$ semestre do curso de Pedagogia da Universidade Federal do Mato Grosso do Sul campus de Ponta Porã. E-mail: mariaelena.aquino2@gmail.com

GODOI, Rozana Vanessa Fagundes Valentim de. Professora efetiva no curso de Artes Visuais na Faculdade de Artes, Letras e Comunicação - FAALC, da Universidade Federal de Mato Grosso do Sul - UFMS. Possui graduação em Educação Artística pela Universidade Federal de Mato Grosso do Sul e Mestrado em Educação pela Universidade Católica Dom Bosco. Atualmente é Doutoranda em Educação pela Universidade Federal da Grande Dourados e integrante do GEPHEMES - Grupo de Pesquisa História da Educação, Memória e Sociedade. E-mail: rozana.valentim@gmail.com

Endereço para correspondência: Maria Elena Aquino Dutra. Rua Adalberto Fróes, 384, Jardim Vitória. Cep. 79.906-778, Ponta Porã/MS. Telefone: (67) 99680-9751. Email: mariaelena.aquino2@gmail.com

Endereço para correspondência: Rozana Vanessa Fagundes Valentim de Godoi. Rua 608, R. Ufms, 468 - Vila Olinda, Campo Grande - MS, Cep. 79070-900. Telefone: (67) 99245-9794. E-mail-rozana.valentim@gmail.com

Como citar este artigo (Formato ABNT): DUTRA, Maria Elena Aquino; GODOI, Rozana Vanessa Fagundes Valentim de. Programa de Escolas Interculturais de Fronteira (PEIF): um desafio para as escolas no Município de Ponta Porã. Educação, Psicologia e Interfaces, v. 3, n.3, p. 35-47, 2019. DOI: https://doi.org/10.37444/issn-25945343.v3i3.209

Recebido: 10/10/2019.

Aceito: 10/11/2019.

Educação, Psicologia e Interfaces, Volume 3, Número 3, p. 35-47, Setembro/Dezembro, 2019. ISSN: 2594-5343. DOI: https://doi.org/10.37444/issn-2594-5343.v3i3.209 